\title{
Restructuring of erythrocytes in persons of mature and elderly age on the background of diabetes mellitus
}

\author{
Tatyana V. Pavlova ${ }^{1} \oplus$, Igor B. Bukhvalov ${ }^{2}\left({ }^{\oplus}\right.$, Anton N. Kaplin $^{3} \oplus$, \\ Irina I. Povalyaeva ${ }^{4}{ }^{\oplus}$, Igor Yu. Goncharov ${ }^{5}{ }^{\oplus}$, Lyubov A. Pavlova ${ }^{1} \mathbb{C}$ \\ ${ }^{1}$ Belgorod State National Research University, \\ 85 Pobedy St., Belgorod, 308015, Russia \\ ${ }^{2}$ Institute of Hematopathology, \\ 75a Fangdieck St., Hamburg, 22547, Germany \\ ${ }^{3}$ Kursk State Medical University, \\ 3 Karl Marks St., Kursk, 305041, Russia \\ ${ }^{4}$ Children's Regional Clinical Hospital, \\ 44 Gubkin St., Belgorod, 308012, Russia \\ ${ }^{5}$ Shukhov Belgorod State Technological University, \\ 46 Kostyukov St., Belgorod, 308012, Russia
}

Corresponding author: Anton N. Kaplin (drkaplin46@gmail.com)

\begin{abstract}
Background: The high incidence of diabetes mellitus in modern conditions dictates the need to search for new, including microscopic, opportunities to identify pathological changes in the course of various physiological processes. The aim of the study: To study the peculiarities of changes in the properties and parameters of erythrocytes in various types of diabetes mellitus (types 1 and 2) in women of mature and elderly age. Materials and methods: Venous blood of 55 women aged 30 to 70 years, divided into study groups (women with type DM, women with type II DM, control without endocrinopathy) was examined using atomic force and scanning probe microscopy. Results: The authors found an increase in the percentage of pathological forms of erythrocytes in patients with diabetes mellitus. An increase in the number of macrocytic forms of erythrocytes was observed not only when compared with the control group (DM I $12.20 \pm 2.14$, DM II - 10.00 \pm 1.20 , control $-4.40 \pm 0.15)$, but and when comparing two age

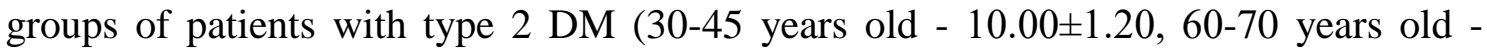
$13.20 \pm 1.90)$. The same tendency is typical for microcytes. Geriatric changes in the geometric parameters of erythrocytes in the group of patients with type 2 DM were characterized by an increase in the volume, as well as the maximum height of erythrocytes with increasing age of the patients. Conclusion: The use of atomic force microscopy in the study of the biophysical parameters of erythrocytes makes it possible to identify pa-
\end{abstract}


tients from high-risk groups by determining such changes as an increase in the number of macrocytes, microcytes and pathologically altered forms of erythrocytes, a decrease in the average volume and area of erythrocytes.

Keywords: geriatrics; diabetes mellitus; erythrocytes; atomic force microscopy

For citation: Pavlova TV, Bukhvalov IB, Kaplin AN, et al. Restructuring of erythrocytes in persons of mature and elderly age on the background of diabetes mellitus. Research Results in Biomedicine. 2021;7(4): 400-409. DOI: 10.18413/2658-6533-2021-74-0-6

Introduction. According to the $\mathrm{WHO}$, currently the total number of people with diabetes in the world has exceeded 100 million (3\% of the world's population). Early disability and mortality, which are mainly caused by diabetic angiopathies, are the most important socioclinic problem of modern diabetology $[1,2,3]$. The problem of diabetes mellitus and its influence on the development of vascular complications $[4,5,6]$, as well as changes in the rheological properties of blood, despite a large number of different studies, remains relevant [7].

For people with diabetes mellitus, the rheological properties of blood are a vital indicator [8-10], since as a result of prolonged hyperglycemia, significant changes occur in the body, the end result of which is an increase in blood viscosity [11], which leads to a decrease in blood flow velocity. As a result of an increase in blood viscosity in combination with a change in the biophysical properties of erythrocytes [12] under the influence of an increased concentration of glucose [13], patients develop stagnation, damage to the endothelial walls of blood vessels, and develop micro- and microangiopathies [14]. Clear changes are undoubtedly taking place at the molecular level as well. The structure of erythrocyte membranes changes, characterized by a change in the lipid phase with disorganization and disruption of the functional properties of the outer and deep layers, as well as protein-lipid interactions.

Disorders of carbohydrate metabolism, specific for diabetes mellitus (especially at the stage of endocrinopathy decompensation), lead to an increase in the proportion of macrocytes and polymorphism in the size of erythrocytes, sphericity of shape, the appear- ance of a significant number of deformed and hemolyzed cells, as well as shadow cells devoid of hemoglobin. Qualitative rearrangements in the erythron system under conditions of prolonged decompensation of glycemia enhance erythrodieresis, decrease the number of erythrocytes circulating in the blood, which, combined with their accelerated aging and a decrease in deformability, enhances tissue hypoxia.

It should be noted that various parameters of erythrocytes undergo significant changes in diabetes mellitus [15, 16, 17], but it is difficult to identify them using standard methods [18]. Therefore, in our study, we tried to consider the possibility of using atomic force microscopy (AFM) to study the cytoarchitectonics and various biophysical parameters [19] of erythrocytes in patients with diabetes mellitus of various types and ages. The use of atomic force microscopy to study micro- and nanoscale areas of the surface of erythrocytes and other blood cells makes it possible to introduce new cellular parameters, to obtain qualitatively new ideas about the causes and mechanisms of changes in their properties in diabetes mellitus.

In their article, the authors tried to study the geriatric features of changes in the properties and parameters of erythrocytes in various types of diabetes mellitus (type 1 and type 2) in women of mature and elderly age using innovative research methods (atomic force microscopy).

Materials and methods. In the course of the study, patients were examined on the basis of the Regional State Budgetary Healthcare Institutions: "City Polyclinic of the City of Belgorod" in the period from 2018 to 2020. Morphological and biochemical devel- 
opments were carried out at the Department of Pathology of the Medical Institute of Belgorod State National Research University, as well as at the Scientific, Educational and Innovation Center "Nanostructured Materials and Technologies" of the Federal State Autonomous Educational Institution of Higher Education "Belgorod State National Research University". 55 women from 30 to 70 years old were selected, who made up the following groups:

1st - women with type I diabetes mellitus at the age of 30-45 (DM I) (15) mellitus

2nd - women with type II diabetes

2A - women with type II diabetes mellitus at the age of 30-45 (10)

$2 \mathrm{~B}$ - women with type II diabetes mellitus at the age of 60-70 (10)

3th - control group - women without endocrinopathies and severe somatic pathology

3A - control group - women without endocrinopathies and severe somatic pathology at the age of 30-40 (10)

3B - control group - women without endocrinopathies and severe somatic pathology at the age of 60-70 (10)

The criterion for inclusion of patients in groups 1 and 2 was the presence of diabetes mellitus, confirmed by appropriate clinical data and examinations.

Blood was taken from a vein by puncture of the cubital vein, the blood was mixed in a test tube with an anticoagulant (heparin). When conducting a laboratory test, we used the method of washing the erythrocyte mass based on the principle of diluting the test material with an isotonic solution, an aqueous solution isotonic to blood plasma, the main reagent of this type is a physiological solution - an aqueous solution of sodium chloride with a mass fraction of $\omega(\mathrm{NaCl}) \approx 0.9 \%$, and its centrifugation. Then the samples were mixed on a defatted glass slide for immunohistochemistry and placed in a humid chamber for scanning. The surface morphology of erythro- cytes was studied using a scanning probe microscope NTEGRA-AURA (NT-MDT, Zelenograd). SPM images were obtained in the mode of semicontact atomic force microscopy (AFM) using cantilevers of the DCP11 series with a radius of curvature of $70 \mathrm{~nm}$. The work was carried out in contact modes of intermittent and constant profile using $\mathrm{Si}$ or $\mathrm{SiN}$ cantilevers, using a low atmospheric vacuum. Statistical processing of the obtained AFM images was carried out using the software package "Image Analysis P9" (NT-MDT). The following geometrical parameters of erythrocytes were calculated: Area is the cross-sectional area of the particle at the level of half the height of the erythrocyte, Volume is the volume of the particle, Max $\mathrm{Z}$ is the value of the local maximum, the height of the erythrocyte measured from the general zero level, Perimeter is the perimeter of the section, Diameter is the effective diameter, defined as the diameter of a circle whose area is equal to the sectional area Diameter =

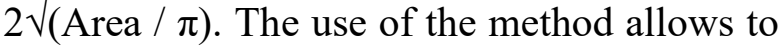
reduce the research time and obtain highresolution scans of cells, while maintaining their viability, native size and shape.

Results and discussion. When analyzing the AFM data in a group of practically healthy people, we obtained data on the state of erythrocytes. It should be noted that with diabetes, stasis, sludge and thrombosis were expressed, which was more pronounced in type 1 diabetes (Fig. 1, 2).

The largest percentage of the erythrocyte population in the control group (woman in age $30-45$ years) was represented by normocytes $(87.30 \pm 1.43)$. The share of microcytes accounted for $6.30 \pm 1.52$, and macrocytes $-6.40 \pm 0.13$ (Fig. 1). As can be seen from the table below, disturbances in carbohydrate metabolism, changes in the membrane and cytoplasm of erythrocytes under the influence of the toxic effect of excess glucose lead to polymorphism of their sizes in all types of diabetes mellitus (Table 1, Fig. 2). 


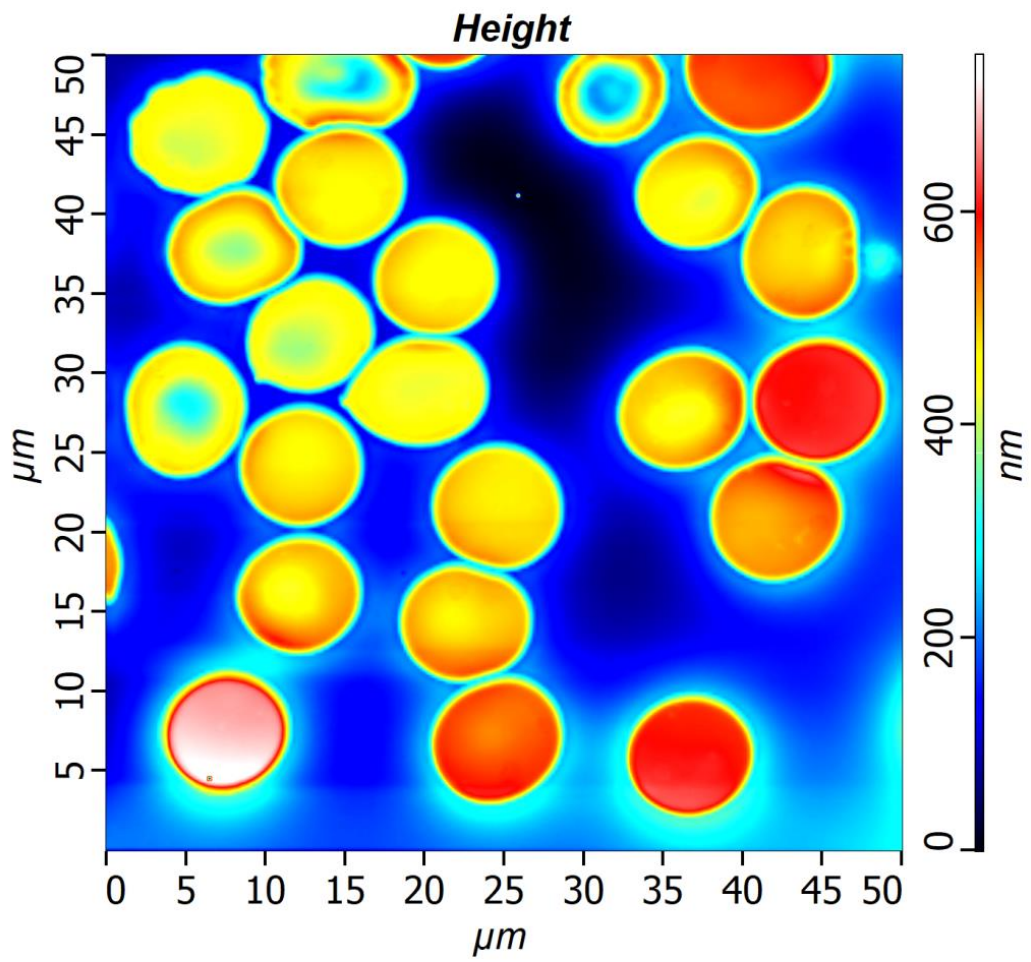

Fig. 1. Erythrocytes of the control group. Woman (30 years). The cells are similar in diameter and similar in shape. Atomic force microscopy. 2D image.

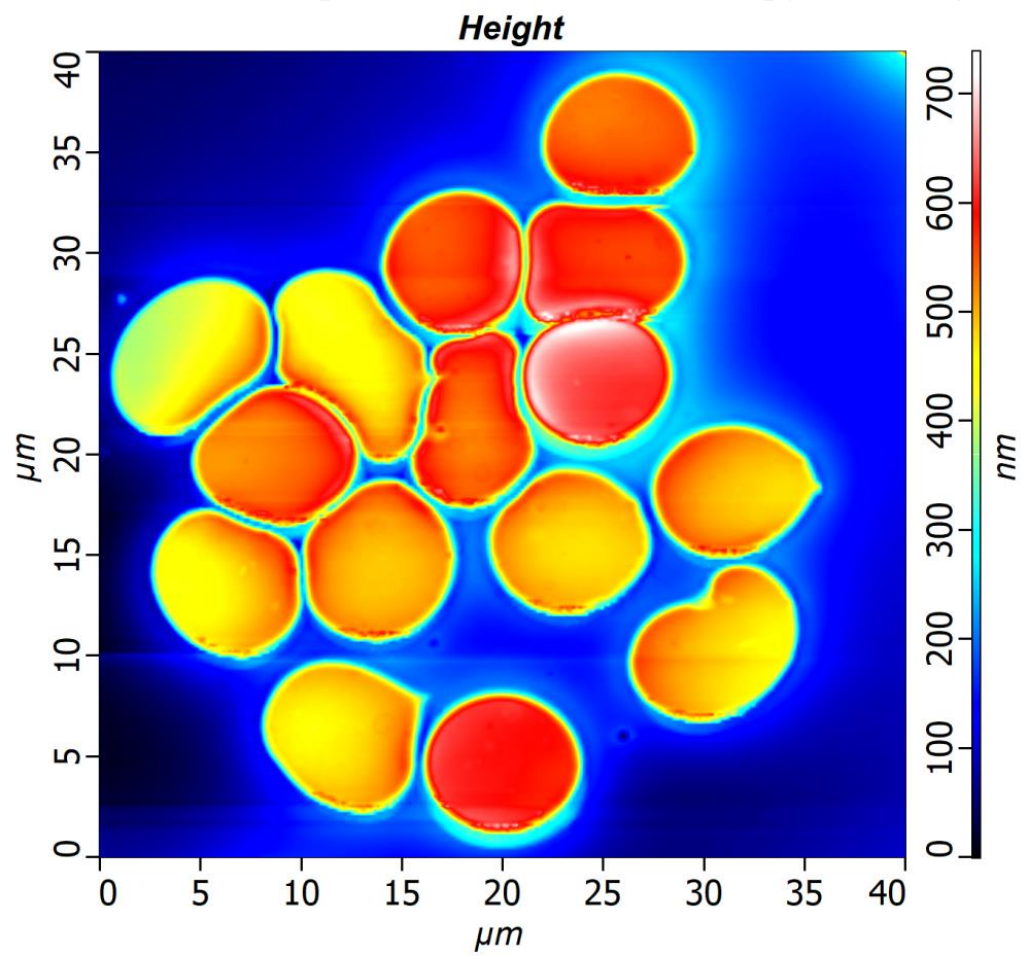

Fig. 2. Erythrocytes of a woman with type I diabetes mellitus (65 years). The cells are of different diameters with a disturbed shape. Erythrocyte sludge. Atomic force microscopy. 2D image.

Although normal sizes remain predominant in populations, the number of both microcytes and macrocytes increases. At the same time, the number of macrocytes also increases, although not so much $(6.30 \pm 0.15)$.
In DM 1, the percentage of microcytes and macrocytes was almost the same $(15.10 \pm 1.50$ and $12.20 \pm 2.14$, respectively), and compared with the control group, the change in the size of erythrocytes was both upward and down- 
ward. Regarding the geriatric aspects of changes in the size of erythrocytes both in normal conditions and in different types of diabetes mellitus, a significant shift towards macrocytic forms can be noted when comparing two age groups in the control group $(4.40 \pm 0.15$ in women aged $30-45$ and $7.30 \pm 0.38$ for women aged $60-70$ years, respectively). At the same time, in the groups of women with type 2 diabetes mellitus, this trend not only persisted, but also worsened due to profound and persistent metabolic changes. So, in the group of women aged 6070 years, suffering from the above pathology, the percentage of macrocytes was maximum and amounted to $13.20 \pm 1.90$.

The ratio of erythrocytes in patients with various types of diabetes mellitus

\begin{tabular}{|c|c|c|c|c|c|}
\hline $\begin{array}{l}\text { Ratio of red blood } \\
\text { cells by size }(\%)\end{array}$ & $\begin{array}{c}\text { Control group } \\
(30-45 \text { years })\end{array}$ & $\begin{array}{c}\text { Control group } \\
(60-70 \text { years })\end{array}$ & $\begin{array}{c}\text { DM 1 } \\
(30-45 \text { years })\end{array}$ & $\begin{array}{c}\text { DM } 2 \\
(30-45 \text { years })\end{array}$ & $\begin{array}{c}\text { DM } 2 \\
\text { (60-70 years) }\end{array}$ \\
\hline $\mathrm{N}$ & 10 & 10 & 15 & 10 & 10 \\
\hline Microcytes & $7.30 \pm 1.50$ & $5.40 \pm 1.40 * *$ & $15.10 \pm 1.50 *$ & $16.50 \pm 1.41 *$ & $8.40 \pm 1.50 * *$ \\
\hline Normocytes & $88.30 \pm 1.40$ & $87.50 \pm 3.60$ & $72.70 \pm 2.30 *$ & $73.50 \pm 2.05 *$ & $78.40 \pm 3.25$ \\
\hline Macrocytes & $4.40 \pm 0.15$ & $7.30 \pm 0.38 * *$ & $12.20 \pm 2.14 *$ & $10.00 \pm 1.20 *$ & $13.20 \pm 1.90 * *$ \\
\hline
\end{tabular}

Note: $* \mathrm{p}<0.05$ in comparison with the group of practically healthy people; $* * p<0.05$ in comparison with a similar group in terms of age

Analysis of the diameter of erythrocytes of different size groups showed that there is no significant change in this parameter, both in the direction of its increase and in the di- rection of decreasing, with different types of diabetes, only very minor fluctuations are observed (Table 2).

The ratio of the sizes of various types of erythrocytes in patients with diabetes mellitus

\begin{tabular}{|c|c|c|c|c|c|}
\hline $\begin{array}{c}\text { Diameter } \\
\text { erythrocytes }(\mu \mathrm{m})\end{array}$ & $\begin{array}{l}\text { Control group } \\
(30-45 \text { years })\end{array}$ & $\begin{array}{c}\text { Control group } \\
(60-70 \text { years })\end{array}$ & $\begin{array}{c}\text { DM } 1 \\
(30-45 \text { years }) \\
\end{array}$ & $\begin{array}{c}\text { DM } 2 \\
\text { (30-45 years) }\end{array}$ & $\begin{array}{c}\text { DM } 2 \\
\text { (60-70 years) } \\
\end{array}$ \\
\hline $\mathrm{N}$ & 10 & 10 & 15 & 10 & 10 \\
\hline Microcytes & $6.40 \pm 0.06$ & $6.1 \pm 0.14$ & $6.60 \pm 0.27$ & $6.55 \pm 0.36$ & $5.02 \pm 0.45$ \\
\hline Normocytes & $7.55 \pm 0.15$ & $7.09 \pm 0.65$ & $7.90 \pm 0.30$ & $7.80 \pm 0.14$ & $7.06 \pm 0.38$ \\
\hline Macrocytes & $8.19 \pm 0.06$ & $8.35 \pm 0.16$ & $8.75 \pm 0.44$ & $8.55 \pm 0.56$ & $8.95 \pm 0.86$ \\
\hline
\end{tabular}

Note: ${ }^{*} \mathrm{p}<0.05$ in comparison with the group of practically healthy people; $* * p<0.05$ in comparison with a similar group in terms of age

With DM, cells of elongated and irregular shape appeared, which may indicate both a violation of the elasticity of the membranes and a difficulty in passing through the microvasculature due to a change in its structure, which is more pronounced in DM 1 (Fig. 2). Individual erythrocytes were connected to each other, as well as to endothelial cells, by cytoplasmic bridges and fibrin filaments (to the greatest extent in type 1 diabetes), which contributed to stasis, sludge and thrombosis.

There was a change in the shape of erythrocytes, a change in the ratio of various forms of erythrocytes with an increase in the percentage of pathologically changed (Table 3). In all types of diabetes mellitus (DM 1, DM 2) in all aged groups, a significant decrease in the number of discocytes was observed $\quad(74.30 \pm 0.62, \quad 77.03 \pm 0.62$, $75.01 \pm 3.60$ respectively, compared with the content of those in the control group in age $30-45$ years $-90.67 \pm 2.44)$. These changes indicate a reduced stability of erythrocyte membranes due to its glycosylation, changes in the lipid composition of the cell membrane, as well as the configuration of protein molecules, violation of the asymmetry and packing of lipids in the membrane bilayer. 
Table 3

The ratio of pathological erythrocytes (by type) in patients with diabetes mellitus (\%)

\begin{tabular}{|l|c|c|c|c|c|}
\hline $\begin{array}{l}\text { Type of eryth- } \\
\text { rocytes }\end{array}$ & $\begin{array}{c}\text { Control group } \\
\text { (30-45 years) }\end{array}$ & $\begin{array}{c}\text { Control group } \\
\text { (60-70 years) }\end{array}$ & $\begin{array}{c}\text { DM 1 } \\
\text { (30- 45 years) }\end{array}$ & $\begin{array}{c}\text { DM 2 } \\
\text { (30- 45 years) }\end{array}$ & $\begin{array}{c}\text { DM 2 } \\
\text { (60-70 years) }\end{array}$ \\
\hline Discocytes & 10 & 10 & 15 & 10 & 10 \\
\hline $\begin{array}{l}\text { Reversibly } \\
\text { modified } \\
\text { (transient) }\end{array}$ & $90.67 \pm 2.44$ & $86.02 \pm 3.89^{* *}$ & $74.30 \pm 0.62^{*}$ & $77.03 \pm 0.62^{*}$ & $75.01 \pm 3.60^{*}$ \\
\hline $\begin{array}{l}\text { Irreversibly } \\
\text { changed (pre- } \\
\text { hemolytic) }\end{array}$ & $0.17 \pm 0.17$ & $3.17 \pm 0.25^{* *}$ & $6.37 \pm 0.50^{*}$ & $6.10 \pm 0.48^{*}$ & $7.30 \pm 1.40^{* *}$ \\
\hline $\begin{array}{l}\text { Degenerative } \\
\text { forms }\end{array}$ & $0.17 \pm 0.17$ & $2.17 \pm 0.17^{* *}$ & $4.00 \pm 0.52^{*}$ & $3.00 \pm 0.32^{*}$ & $5.20 \pm 0.30^{* *}$ \\
\hline
\end{tabular}

Note: $* \mathrm{p}<0.05$ in comparison with the group of practically healthy people; $* * \mathrm{p}<0.05$ in comparison with a similar group in terms of age

It should be noted that in the control group, with increasing age of the subjects, there is also a decrease in the number of normal discocytic erythrocytes $(86.02 \pm 3.89$ in the age group of 60-79 years compared to $90.67 \pm 2.44$ in the age group of $30-45$ years). It also follows from Table 3 that the process of changing the ratio of various forms of erythrocytes with a predominance of pathologically altered forms is physiological in nature, which attracts attention when comparing the results in groups of relatively healthy people of different ages (the percentage of prehemolytic and degenerative forms significantly increases).

The same tendency is observed in the ratio of types of erythrocytes in patients of different ages with type 2 diabetes mellitus. Thus, the maximum shift towards the prevalence of pathologically altered forms is observed in the group of women with type 2 diabetes mellitus aged 60-70 years. The percentage of prehemolytic forms was $7.30 \pm 1.40$, which is significantly more than two times higher than that in the group of healthy women of the same age (3.17 \pm 0.25$)$, as well as in the group of younger women with the same pathology $(6.10 \pm 0.48)$. Degenerative forms of erythrocytes were also significantly more frequent.

With endocrine pathology, such types of degenerative cells as acanthocytes, cells in the form of a "deflated ball" appeared, which is especially clearly seen when using AFM due to a change in the color of cells associated with a reformation of their diameter. The so- called vesicular cells and even schistocytes, which are fragments of destroyed cells, appeared. All these types with a violation of the structure of cells cannot be restored. They belong to the group of irreversibly deformed or prehemolytic.

The number of cells with hemolysis increased. The surface of the cells was uneven. The architectonics of plasma processes on the surface of erythrocytes was impaired, which is especially noticeable in type 1 diabetes.

When studying the cytoarchitectonics of erythrocytes using a scanning probe microscope, changes in various parameters were shown for different types of diabetes (Table 4).

Both DM 1 and DM 2 these parameters were characterized by a decrease in comparison with the control group. The average area of erythrocytes in DM 1 was $33.50 \pm 1.40 \mu \mathrm{m}^{2}$, in DM 2 (both age groups) $-32.20 \pm 1.50$ and $33.10 \pm 1.90 \mu \mathrm{m}^{2}$ (control $-43.00 \pm 1.10 \mu \mathrm{m}^{2}$ ), and the average volume $-4.40 \pm 0.40 \mu \mathrm{m}^{3}$ in DM 1 and $4.50 \pm 0.30 \mu \mathrm{m}^{3}$ in DM 2. Due to a decrease in both of the above parameters, the ratio of the cell surface area to its volume still does not undergo fatal disturbances and retains a value close to normal. At the same time, the average maximum height of erythrocytes in both groups significantly increased, the cells took on a more elongated shape, different from the correct discoid. With DM 1 and DM 2 (both age groups), such a parameter as the average diameter of the erythrocyte also decreased, and amounted to $6.30 \pm 0.45$ $\mu \mathrm{m}$ and $6.40 \pm 0.60,6.90 \pm 0.70 \mu \mathrm{m}$, respectively. 
Table 4

Parameters of erythrocytes in various types of diabetes mellitus

\begin{tabular}{|c|c|c|c|c|c|}
\hline Group & $\begin{array}{c}\text { Average } \\
\text { erythrocyte area, } \\
\boldsymbol{\mu m}^{2}\end{array}$ & $\begin{array}{c}\text { Average } \\
\text { erythrocyte } \\
\text { volume, } \boldsymbol{\mu m}^{3}\end{array}$ & $\begin{array}{c}\text { Average maximum } \\
\text { erythrocyte height, } \\
\boldsymbol{\mu m}\end{array}$ & $\begin{array}{c}\text { Average } \\
\text { erythrocyte } \\
\text { perimeter, } \boldsymbol{\mu m}\end{array}$ & $\begin{array}{c}\text { Average } \\
\text { erythrocyte } \\
\text { diameter, } \boldsymbol{\mu m}\end{array}$ \\
\hline Control A & $43.00 \pm 1.10$ & $5.50 \pm 0.70$ & $0.55 \pm 0.07$ & $0.29 \pm 0.03$ & $7.40 \pm 0.30$ \\
\hline Control B & $44.00 \pm 1.20$ & $5.70 \pm 1.10$ & $0.51 \pm 0.09$ & $0.30 \pm 0.05$ & $7.70 \pm 0.40$ \\
\hline DM 1 & $33.50 \pm 1.40^{*}$ & $4.40 \pm 0.40 *$ & $0.65 \pm 0.04 *$ & $0.42 \pm 0.06 *$ & $6.30 \pm 0.45^{*}$ \\
\hline DM 2 A & $32.20 \pm 1.50^{*}$ & $4.50 \pm 0.30 *$ & $0.67 \pm 0.06 *$ & $0.43 \pm 0.07 *$ & $6.40 \pm 0.60^{*}$ \\
\hline DM 2 B & $33.10 \pm 1.90^{*}$ & $5.90 \pm 0.50^{* *}$ & $0.81 \pm 0.15^{* *}$ & $0.49 \pm 0.09$ & $6.90 \pm 0.70^{*}$ \\
\hline
\end{tabular}

Note: $* p<0.05$ in comparison with the group of practically healthy people; $* * p<0.05$ in comparison with a similar group in terms of age

The geometric parameters of erythrocytes in both age groups of healthy women did not differ significantly. Geriatric changes in the geometric parameters of erythrocytes in the group of patients with type 2 diabetes mellitus were characterized by an increase in volume $\left(4.50 \pm 0.30 \mu \mathrm{m}^{3}\right.$ and $\left.5.90 \pm 0.50 \mu \mathrm{m}^{3}\right)$, as well as the maximum height of erythrocytes $(0.67 \pm 0.06 \mu \mathrm{m}$ and $0.81 \pm 0.15 \mu \mathrm{m})$ with increasing age of the patients.

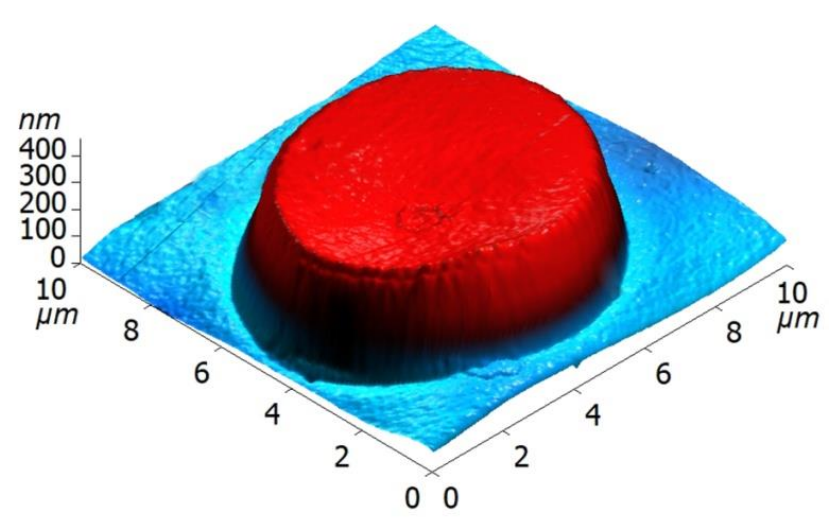

When analyzing the cells' images obtained using AFM scans, a change in the depth of the erythrocyte cavity was noted in different types of diabetes mellitus. Thus, the erythrocytes of patients in the control group were characterized by a preserved discoid biconcave shape with a moderate depth of the cavity, which is physiologically optimal characteristics (Fig. 3).

Fig. 3. Erythrocyte of a woman (40 years) in the control group. Moderate depth of the cavity of the cell. Atomic force microscopy. Fig. A - three-dimensional image, Fig. B - graphic image.

In DM 2, although some concavity was present on the erythrocyte, its depth was still less than in the control group (Fig. 4). It should be noted that the age of the patients who made up the second study group (with type 2 diabetes mellitus) was, on average, more; they also more often had overweight, increased lipoprotein levels and their fractional imbalance, which may also deny a signifi- cant effect on the molecular composition of cellular membranes of erythrocytes, changing its plasticity and leading to the loss of the ability to efficiently circulate in the capillaries. At the same time, a similar effect can be observed in the long-term course of type 1 diabetes mellitus due to the long-term, earlyformed hyperglycemic state. 

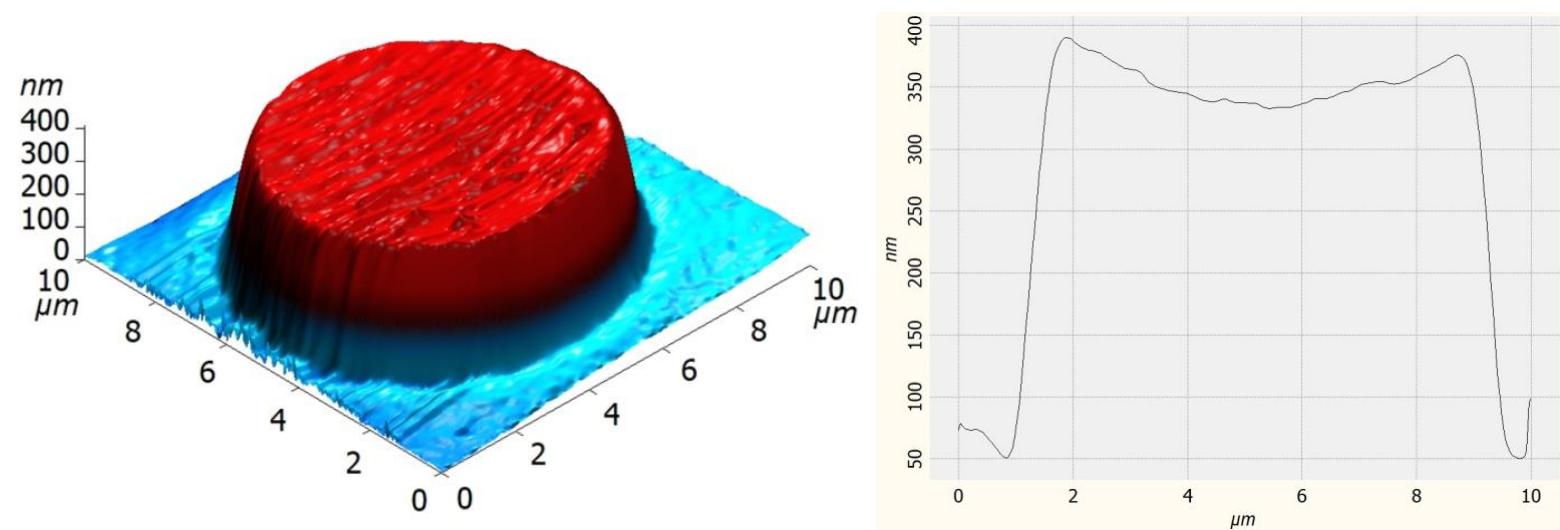

Fig. 4. Red blood cell of a woman with (65 years) type 2 diabetes. The depths of the depression on the cell surface are less than in the control group. Atomic force microscopy. Fig. A - threedimensional image, Fig. B - graphic image.

Completely different changes in the shape of the erythrocyte were observed in DM 1. A significant decrease in the depth of the cavity on the surface of the erythrocyte, accompanied by the unevenness of its surface, was accompanied by a decrease in both the

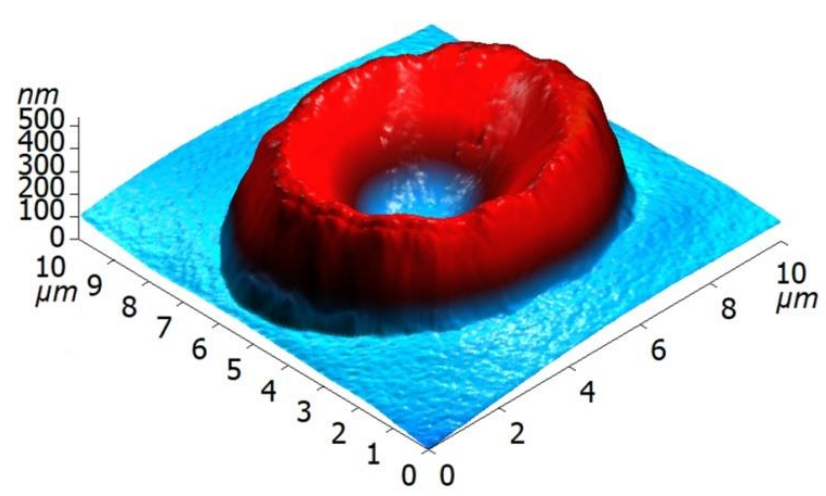

Fig. 5. Erythrocyte of a woman (32 years) with type 1 diabetes mellitus. Significant increase in the depth of the cavity on the cell surface. Atomic force microscopy. Fig. A - three-dimensional image, Fig. B - graphic image.

Of course, the presence of pathology of the endocrine system in old and old age contributes to significant, in comparison with those in practically healthy people, biochemical and electron-microscopic changes in erythrocytes, which are directly proportional to the duration of the course and stage of the disease $[2,5]$. Despite the fact that the profile of changes in hematological parameters and morphometric characteristics can be assessed as a manifestation of adaptive processes in the erythrocyte system aimed at increasing the volume and the area of the cell (Fig. 5). However, as with the opposite changes, this contributed to the violation of the deformability of erythrocytes when passing through the vessels, to a decrease in the maximum possible number of molecules carried on the surface.

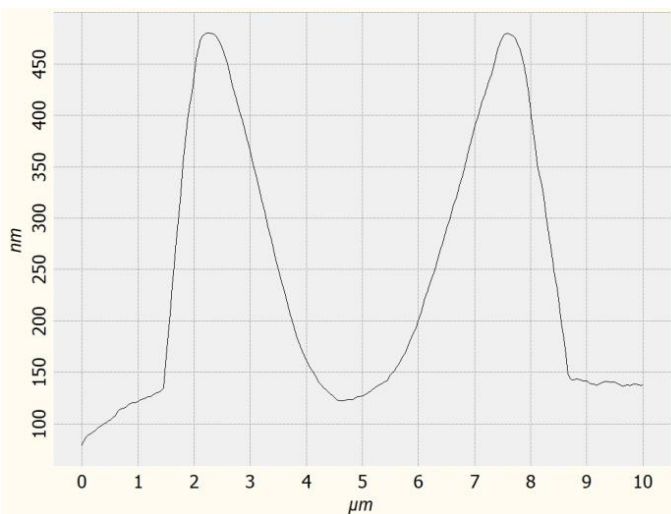

rheological properties of blood and reducing tissue hypoxia, their long-term preservation leads to a violation of adaptation mechanisms and exacerbation of pathological processes $[10,17]$. So, such changes in diabetes mellitus include the presence of a large number of cells of an elongated and irregular shape, a decrease in the percentage of normocytic forms due to an increase in both microcytes and macrocytes in various types of diabetes, a significant change in the cytoarchitectonic parameters of erythrocytes: a decrease in both 
the average volume and the average area of erythrocytes.

Conclusion. The use of atomic force microscopy in the study of the rheological properties of blood, the biophysical parameters of erythrocytes is justified, since it allows not only to obtain information about the degree of change in their ability to deform, but also to detect changes that contribute to the development of microangiopathy in the early stages.

\section{Financial support}

No financial support has been provided for this work.

\section{Conflict of interests}

The authors have no conflict of interest to declare.

\section{References}

1. Pavlova TV, Petrukhin VA, Malyutina ES, et al. New information in the study of clinical and morphological aspects of endocrinopathies in pregnant women. Russian Bulletin of Obstetrician-Gynecologist $=$ Rossiiskii vestnik akusheraginekologa. 2020;20(5):13-20. Russian. DOI: https://doi.org/10.17116/rosakush20202005113.

2. Westerman M, Porter JB. Red blood cell-derived microparticles: an overview. Blood Cells, Molecules, and Diseases. 2016;59:134-139. DOI: https://doi.org/10.1016/j.bcmd.2016.04.003

3. Fowler MJ. Microvascular and macrovascular complications of diabetes. Clinical Diabetes. 2008;26(2):77-82. DOI: https://doi.org/10.2337/diaclin.26.2.77

4. Alexandru N, Badila E, Weiss E, et al. Vascular complications in diabetes: microparticles and microparticle associated MicroRNAs as active players. Biochemical and Biophysical Research Communications. 2016;472(1):1-10. DOI: https://doi.org/10.1016/j.bbrc.2016.02.038

5. Vilahur G. Red Blood Cells Deserve Attention in Patients With Type 2 Diabetes. Journal of the American College of Cardiology. 2018;72(7):781-783. DOI: https://doi.org/10.1016/j.jacc.2018.05.053

6. Kontomaris SV, Grant C, Alexandratou E. Atomic Force Microscopy: In Sickness and in Health. Scanning. 2019:6149247. DOI: https://doi.org/10.1155/2019/6149247

7. Yeow N, Tabor RF, Garnier G. Atomic force microscopy: From red blood cells to im- munohaematology. Advances in Colloid and Interface Science. 2017;249:149-162. DOI: https://doi.org/10.1016/j.cis.2017.05.011

8. Szablewski L, Sulima A. The structural and functional changes of blood cells and molecular components in diabetes mellitus. Biological Chemistry. 2017;398(4):411-423. DOI: https://doi.org/10.1515/hsz-2016-0196

9. Kaur R, Kaur M, Singh J. Endothelial dysfunction and platelet hyperactivity in type 2 diabetes mellitus: molecular insights and therapeutic strategies. Cardiovascular Diabetology. 2018;17(1):121.

DOI: https://doi.org/10.1186/s12933-018-0763-3

10. Suryavanshi C, Manjula SD, Ragini B, Raghavendra Rao K. Association of increased levels of glycated hemoglobin with variations in red blood cell parameters in diabetes mellitus. International Journal of Advanced Research. 2015;3:31-37.

11.Pavlova T, Prashchayeu K, Pozdnyakova N, et al. Erythrocytes as target cells of diabetes types 1 and 2. Virchows Archiv. The European Journal of Pathology. 25th European Congress of Pathology. European Society of Pathology. 2013;157-158.

12.Kojima H, Kim J, Chan L. Emerging roles of hematopoietic cells in the pathobiology of diabetic complications. Trends in Endocrinology and Metabolism. 2014;25(4):178-187. DOI: https://doi.org/10.1016/j.tem.2014.01.002

13.Ruggeri FS, Sneideris T, Vendruscolo $\mathrm{M}$, et all. Atomic force microscopy for single molecule characterisation of protein aggregation. Archives of Biochemistry and Biophysics. 2019;664:134-148. DOI: https://doi.org/10.1016/j.abb.2019.02.001

14. Nada AM. Red cell distribution width in type 2 diabetic patients. Diabetes, Metabolic Syndrome and Obesity: Targets and Therapy. 201;8:525-533.

DOI: https://doi.org/10.2147/DMSO.S85318

15. Gkaliagkousi E, Nikolaidou B, Gavriilaki E. et all. Increased erythrocyte- and plateletderived microvesicles in newly diagnosed type 2 diabetes mellitus. Diabetes and Vascular Disease Research. 2019;16(5):458-465. DOI: https://doi.org/10.1177/1479164119844691

16. Chang HY, Li X, Karniadakis GE. Modeling of Biomechanics and Biorheology of Red Blood Cells in Type 2 Diabetes Mellitus. Biophysical Journal. 2017;113(2):481-490. DOI: https://doi.org/10.1016/j.bpj.2017.06.015

17.Fornal M, Lekka M, Pyka-Fościak G, et al. Erythrocyte stiffness in diabetes mellitus stud- 
ied with atomic force microscope. Clinical Hemorheology and Microcirculation. 2006;35(12):273-276.

18.Kuznik BI, Vitkovskiy YuA, Zakharova $\mathrm{MYu}$, et al. Aggregation activity of blood formed elements in patients with type 1 and type 2 diabetes mellitus. Diabetes mellitus. 2012;15(2):49-53. Russian. DOI: https://doi.org/10.14341/20720351-5518

19.Pavlova TV, Malyutina ES, Selivanova $\mathrm{AV}$, et al. New approaches in assessing the clinical and pathomorphological aspects of obstetric pathology in the structure of the mother-placentafetus using atomic force research. Systematic Reviews in Pharmacy. 2020;11(6):21-25. DOI: https://doi.org/10.31838/srp.2020.6.05

Received 5 June 2021

Revised 10 September 2021

Accepted 23 September 2021

\section{Information about the authors}

Tatyana V. Pavlova, Doct. Sci (Medicine), Professor, Head of the Department of Pathology, Belgorod State National Research University, Belgorod, Russia, E-mail: pavlova@bsu.edu.ru, ORCID: https://orcid.org/0000-0003-2360-2875.
Igor B. Bukhvalov, Doct. Sci (Biology), Professor, Head of the Laboratory of Immunohistochemistry, Institute of Hematopathology, Hamburg, Germany, E-mail: buchwalow@ @athologie-hh.de, ORCID: https://orcid.org/0000-0003-1142-7483.

Anton N. Kaplin, Cand. Sci (Medicine), Senior Lecturer, Head of the Department of Pathological Anatomy, Kursk State Medical University, Kursk, Russia, E-mail: drkaplin46@gmail.com, ORCID: https://orcid.org/0000-0001-5968-7132.

Irina I. Povalyaeva, Deputy Chief Physician of the Children's Regional Clinical Hospital, Belgorod, Russia. E-mail: irina87iva@mail.ru, ORCID: https://orcid.org/0000-0001-7231-6010.

Igor Yu. Goncharov, Cand. Sci (Physics and Mathematics), Associate Professor at the Department of Physics, Shukhov Belgorod State Technological University, Belgorod, Russia. E-mail: goncharov@bsu.edu.ru, ORCID: https://orcid.org/0000-0002-7734-0535.

Lyubov A. Pavlova, Doct. Sci (Medicine), Professor, Associate Professor at the Department of Pathology, Belgorod State National Research University, Belgorod, Russia, E-mail: Lpavlova1@yandex.ru, ORCID: https://orcid.org/00000002-5537-2157. 